\title{
Here Today, Here Tomorrow: Considering Options Theory in Digital Platform Development
}

\author{
Ted Saarikko \\ Department of Informatics, Umeå University, Umeå, Sweden \\ ted.saarikko@informatik.umu.se
}

\begin{abstract}
Past decades have seen business platforms proliferate not only as a means to collaborate, but also decrease time-to-market and promote innovation. However, extant literature tends to dichotomise platforms, perceiving them as either strategic resources or technical systems. Applied to digital platforms, we argue that options theory offers a potential means to reconcile the operand and operant perspectives of platform artefacts. We illustrate our point via a case study of a firm that has gradually developed a product that enables mobile communication into a digital platform that provides a wide range of customers with services from several different suppliers. This study contributes to our understanding of digital platforms as it describes how design choices by a provider can affect flexibility and continued development of new services.
\end{abstract}

Keywords: Digital platform, digital options, options value, real options, ecosystem.

\section{Introduction}

In light of increased complexity and competition, firms are increasingly becoming aware of the impracticality of developing the technology to solve all of their problems on a case-by-case basis. One means to manage complexity as well as economise on development is through the use of platforms. The platform concept lends itself to several perspectives that may be broadly dichotomised into the platform as a modular core that permits variations on a theme [1] on the one hand, and the platform as a shared structure that facilitates connectivity between parties [2, 3].

As different streams of research tend to pursue their own agenda, they leave in their wake a conceptualisation of platforms that is unclear at best and polysemic at worst. Business literature describes how transactions between actors can be facilitated via multi-sided platforms (e.g. [4, 5]). However, these studies tend to pay little attention to the artefacts we need to enact connectivity. Conversely, IS literature tends to focus on development or governance of the artefact, stopping short of the manner in which they are applied in a business context (e.g. [4], [6]). In essence, there is a tangible divide between studying platforms as operant resources that enable activities, and operand resources as objects of study [7, 8]. As artefacts, platforms are physical (or digital) composite objects of significant complexity. Viewed as operand resources, one is concerned with the prerequisites for creating a platform, e.g. technical requirements, 
design choices, or affordances. However, as platforms are intended to serve as a basis for other applications and uses, it is equally viable to view them as operant resources, i.e. resources that interact with other resources in order to further some ultimate aim. It is therefore not sufficient to study them as either designed artefacts or strategic enablers, but to adopt a composite view whereby both perspectives are equally germane.

We argue that options theory, subdivided into real options and digital options, offers a potentially fruitful means to study the development of platform as an operand resource as well as its appeal for potential users as an operant resource. Although options theory has frequently been applied to information technology (e.g. [9, 10, 11, 12]) and to some extent internal IT platforms (e.g. [13, 14, 15]), it has to the author's knowledge not received any significant attention as a framework for studying the design and diffusion of a platform qua commercial offering. In an effort to address operand as well as operant perspectives, we seek to explore how options drive the evolution of a digital platform and enable flexibility in application. We illustrate our reasoning using a case study of a SME located in Northern Europe that has developed and marketed a digital platform in several industries over the past 13 years.

The paper opens with an outline of platform literature with particular emphasis on digital platforms. Following that, we outline the two streams of options theory: Real options and digital options. We then account for the methodological approach and the case studied before moving on to present the results. The paper concludes with a discussion related to our findings.

\section{$2 \quad$ Related Research}

The following chapter briefly outlines related research in platforms literature.

\subsection{The Platform Concept}

The platform concept first came into wide usage in large-scale manufacturing industries where the seemingly incongruent pursuits of mass production and consumer customisation bought about modularisation and the use of standardised components [16]. In a broader sense, the platform concept has attained "wide usage in management literature as a term meaning foundation of components around which an organization [sic] might create a related but differentiated set of products or services" $[17$, p.36]. Although originally applied predominantly to physical products [1], the discourse has expanded to include distinctly non-material components such as software [18].

Another quality of platforms is their potential to bring multiple actors together around a common structure and thus facilitate connectivity and foster exchange where this would be costly or otherwise impractical [2]. We may distinguish between four platform types depending on their scope: Internal platforms that are used within a firm, supply chain platforms that follow a specific value-added process among several firms, industry platforms that serve as a hub for related or unrelated actors, and multisided platforms that are essentially open marketplaces that facilitate transactions [19]. The two latter types, industry platforms and multi-sided platforms, have garnered 
special attention in relation to novel business models as they are typically accompanied by an ecosystem of backing firms that supply modules or complements that are specific to that platform [18].

A key feature of platforms is their relative stability over time. They have a fixed set of attributes that allows users to interact with the platform and utilise its functionality [20]. Should the manner in which we interact with the platform change on a regular basis, the utility of the platform would diminish as we would no longer have a stable, long-term baseline for which to develop complements [1]. The temporal dimension is also relevant in differentiating between products and platforms. Products are typically isolated entities oriented towards short-term profits and limited life spans, whereas platforms are motivated by the long-term benefit of facilitating the continuous development of new products or services. The distinction between platforms and products has however become increasingly blurry as a physical product may serve as a platform for digital content or services, making the product a stable foundation for complements. This phenomenon has grown increasingly prevalent over the past few years and serves as a basis for a new kind of platform - the digital platform.

\subsection{Digital Platforms}

The advent of digital technologies has opened up several new possibilities as they allow us to operate upon digital objects that are considerably more pliant than their physical counterparts [21]. The flexibility of digital technologies allows content and services to converge so that we may transmit them using the same standardised channels [22]. Furthermore, devices enabled by digital technologies are no longer limited to a single configuration, but malleable in the sense that their applicability can be altered without interfering with their material properties [23].

Our growing understanding of digital materiality carries with it several corollaries, one of which is that platforms are no longer dependent upon the modularity of physical components. A fixed technical architecture could well be dynamic with regards to the ability to add or replace digital components over time. Hence, artefacts that are static in a physical sense may at the same time be digitally modular, permitting us to consider them digital platforms [24]. While the basic tenets of platform modularity still hold true (i.e. a stable core and interchangeable components), properties such as independence from specific channels of delivery as well as post hoc versatility do have profound bearing on how we can approach digital platforms. Yoo et al. [24] suggest a conception whereby the digital platform encompasses four layers: Device, network, service, and content. The ability to disaggregate the platform into these separate, largely independent layers offers us some idea of the potential afforded by combining digital and physical components. Any one of the four layers of a digital platform could be replaced or upgraded without the necessity to amend or replace the remaining three layers, allowing different aspects of the platform to develop at a different pace. Hence, the platform may be perceived as a stable structure upon which to build common services or business processes while it is at the same time offers significant potential for customisation to suit individual needs and preferences.

The ability of digital platforms to remain stable yet concurrently flexible brings about tremendous potential for different types of innovation [22]. More importantly, they offer favourable conditions for continuous development and complements as 
digital objects are not dependent upon physical manufacturing facilities or cumbersome logistics. In some cases complements can even be created without involvement from the proprietor of the platform [25]. As such, the owner could conceivably appropriate significant rents in permitting access whilst at the same time incurring moderate expenditures in maintenance and development, as is the case with applications for smartphones or software for computers. The combination of high profit margins for proprietors and easy access to solutions for adopters makes platforms an appealing commodity [4], [17], [23], but it also exposes all concerned to increased complexity as contexts and technologies interact in ways that neither party may be able to predict. In essence, the choices made by providers and adopters affect the viability of a platform as a whole, yet they are made with a limited view of available choices and ensuing consequences. It therefore stands to reason that there is much to gain from elucidating options in a manner that is germane to providers as well as adopters.

\section{Options Theory}

While options theory represents a diverse field in its own right, we will limit ourselves to the areas of real options and digital options.

\subsection{Real Options}

Options theory is rooted in financial literature and outlines how firms may pursue investments whilst still minimising risk. Simply put, financial options state that a firm first makes a limited investment which creates an option to acquire an asset. The option grants preferential access to the object of interest and can be activated through a second, larger, investment [26]. Management literature expands upon financial options under the guise of real options, a broader construct that provides insight into how tangible as well as intangible resources can enable options for strategic action [27]. Bowman and Hurry [28] describe the activation of options as a form of incremental decision-making on investments that originate with what they refer to as shadow options - options that are present but not recognised - that only become real options following a process of sense-making [29] or exploration [30]. The identification of real options is to a significant extent subject to contingencies such as technological frames [31], experience [32] and absorptive capacity [33] established by past investments, making the identification of real options virtually unique to every firm. After recognising an option as such, the real option may then be acted upon immediately or left unattended for a considerable amount of time depending upon the situation [28], [14]. Once the holder decides to act, the choices are to either abandon (sell) it or adopt (buy) it. The act of adopting an option may be further subdivided depending upon whether the option represents a continuation of existing strategies or whether it offers flexibility to modify organisational means or ends. Adopted options then give rise to new shadow options that will have to be identified as the cycle begins again. 


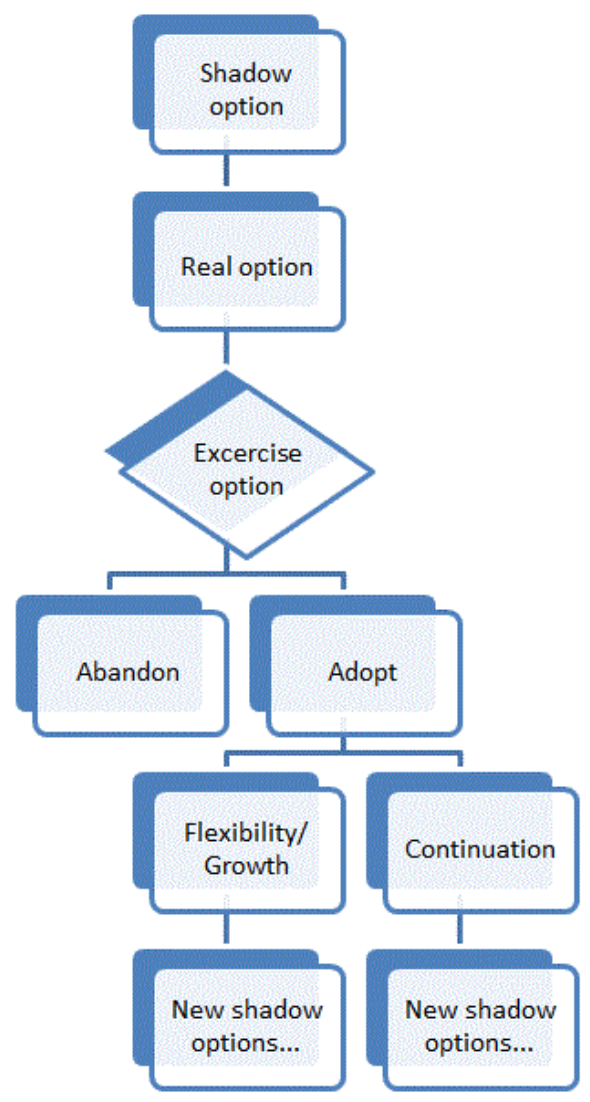

Fig. 1. Real options, adapted from [28]

Real options theory may be transposed onto technology investments insofar as shadow options represent possible avenues of pursuit, real options correspond to developed technologies, and exercising an option equals commercialising or implementing a technology [34]. It is vital to exercise good judgment as moving through this sequence of event cycle too quickly or out of step with technology trends can incur significant liabilities such as infrastructure costs and co-specialised components. The difficulty of evaluation is a perennial feature in IT-investments [35] with particular salience for platforms $[13,14]$ that primarily serve to enable other functions or services. Under these circumstances, flexibility options may be described as technology positioning investments that represent the cost of attaining a subsequent set of attractive growth options that generate additional options rather than serve current operational needs [34], [36]. While single-purpose artefacts or technologies may be relatively easy to perceive (and evaluate) as a real option, investments in platforms are problematic as they represent significant costs yet only provide vicarious benefits as an infrastructure for further options [13]. The malleable nature of digital technologies may be an additional source of concern as they are ubiquitous yet often require special skills in order to progress beyond unrealised shadow options. With this in mind, we turn our attention to managing options related to digital technologies. 


\subsection{Digital Options}

Information technology is not only a significant factor in overall firm performance, but also a generator of options that help organisations leverage internal and external resources to their advantage. Sambamurthy, Bharadwaj and Grover [37] followed by Overby, Bharadwaj and Sambamurthy [38] offer a novel perspective on real options in the form of digital options which they operationalize as the impact of IT upon the reach and richness of organisational processes and knowledge. Sambamurthy et al. argue that accessing digital options is commensurate to cultivating inimitable resources [39], describing it "a set of IT-enabled capabilities in the form of digitized [sic] enterprise work processes and knowledge work" [37, p.247]. While the concept of digital options has been applied in studies on ERP-systems (e.g. [40]), it has also received criticism for its apparent lack of detail on certain key aspects. Sandberg, Mathiassen and Napier [15] argue that restricting digital options to reach and richness limits the concept's generative potential as well as its relevance to IT capabilities. A preferable alternative would be to conceptualise digital options in a manner more closely related to real options theory.

Woodard, Ramasubbu, Tschang and Sambamurthy [41] adapt digital options to an environment where firm strategy is dependent upon co-development of physical and digital components in forming appealing products and/or services. A salient challenge in operating under these conditions is the ability to promote long-term stability and evolution whilst concurrently extracting short-term profits. The authors argue that the locus for digital options is design capital, which in turn is formed of two qualities: Option value and technical debt. Option value describes the possibilities enabled by the composition of the product or service, encompassing a wide span of features ranging from underlying technical architecture to software-enabled interface. The authors relate option value to generativity [42] in that it permits relatively inexpensive alterations to the original design, e.g. in the form of new product models by the producer or customisation by the consumer. Conversely, technical debt describes limitations in the design that restrict the ability to modify the product or service without incurring significant costs. While restricting the design ultimately serves to limit future development of a product or service, it may be necessary in light of practical considerations such as product cost or R\&D expenditures.

Options value and technical debt are not opposites, but rather orthogonal qualities that may be envisioned as a matrix which the firm traverses via design moves. It is possible to alter the options value without incurring or decreasing technical debt - and vice versa. While ostensibly simple, the underlying actions are by no means straightforward as digital business strategies are dependent upon composite physical-digital goods. Each type of materiality offer their own set of possibilities and limitations [21], some of which are emergent and only appear when combined. It is also worth considering that design moves are not necessarily perfectly rational or optimal, but are frequently influenced by external contingencies like availability of resources, influences from partners, or demands from customers. 


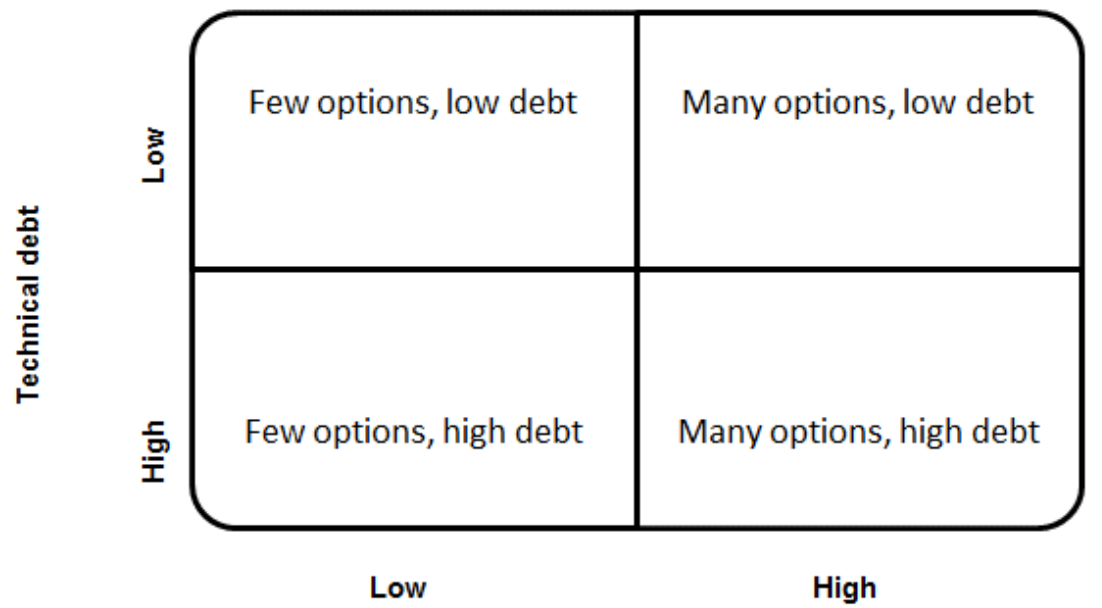

Option value

Fig. 2. Design capital [41]

\section{Research Method}

The objective of the present study is to address the question of how platform evolution relates to the provision of options for application as well as further development. We have pursued this line of inquiry using a single case study [43] centred on a firm that provides a platform for secure communication. As the scope of the study is limited to suggesting means to study a particular phenomenon, the study can be categorised as an explorative study, which is also in keeping with the single-case approach. A qualitative study based on interviews was motivated by the retrospective nature of the study and the unfamiliarity of the researchers with the specific business context. Interviews permit informed answers and access to the expertise of informants, permitting "in-depth studies [...] in plain and everyday terms" [43, p.6]. The object of the study is to garner insight into the actions taken by a firm to meet changing business priorities and technological opportunities. Hence, case study allowed appeared the most viable option as it "studies a phenomenon [...] in its real-world context" [43, p.17].

Empirical data was gathered primarily through five separate interviews with employees, with additional contextual information provided by documentation pertaining to the platform and attention in three meetings with representatives from the firm. Given that the provider is a small firm consisting of some twenty employees, five interviews with high-level staff were deemed sufficient to grasp the aim and scope of the platform.

All interviews were conducted at the offices of the firm and ranged from 45 to 70 minutes in length. The interviews may be considered semi-structured [44] as the interviewer prepared a number of questions beforehand, but also followed up on a priori unexpected or unknown avenues of inquiry that presented themselves. 
Table 1. Outline of interviews

\begin{tabular}{|l|c|}
\hline Position & $\begin{array}{c}\text { No. of } \\
\text { interviews }\end{array}$ \\
\hline Chief Executive Officer & 2 \\
\hline Business Area Manager & 1 \\
\hline Chief Operation Officer & 1 \\
\hline Area Sales Manager & 1 \\
\hline
\end{tabular}

Following transcription, the empirical material was compiled and disassembled guided by the theoretical framework used in this paper. The material was then reassembled thematically using the categories of the framework in an iterative fashion. Analysis was conducted using a bricolage approach where patterns and themes were sought based on a theoretically informed reading of the empirical material [45] with the aim of deducing what aspects of the situated context is amenable to abstraction and contribution to a wider body of knowledge. As the number of interviews conducted is relatively small, no particular software or similar tool was used in the coding and analysis of the empirical material.

\section{Case Study}

Our study centres on PlatformCo, an enterprise founded in 2000 located in northern Europe that currently houses a staff of $20+$ employees. PlatformCo is a branch of a larger firm that is in the business of inventing, developing and selling wired communications systems for emergency use. In its particular niche, the aggregate firm has managed to establish a small yet firm foothold, but profit-margins are relatively low and the competition fierce. With that in mind, PlatformCo pursued an alternative business model and started branching out in the early 2000's by seeking to apply technical skills pertaining to communication in other areas. They sought diversification by developing a communication platform, PlatformCoMobile, which marked two distinct points of departure from the existing business model. First, the platform was designed to facilitate machine-to-machine communication rather than vocal communication between people or interaction between human and system. Second, the idea was to use the platform to sell services as opposed to off-the-shelf products to customers in an effort to increase profit margins. While this upward mobility in the value chain was desirable from a business perspective, it also represented a significant increase in the level of complexity as service-orientation forced closer ties to customers.

In practical terms, PlatformCoMobile is composed of a communications platform that is physically installed into the user's system where it serves as a link to backoffice system(s) where services are hosted. The communications platform is composed of a highly customised router and Linux-based software that is intended to provide security and stability. The platform may be integrated into user systems using several means; including common interfaces like Ethernet and Universal Serial Bus (USB) as well as the more specialised Controller Area Network (CAN) Bus which is 
widely used in automotive applications. PlatformCoMobile also supports a range of wireless communication protocols and is equipped to make use of the Global Positioning System.

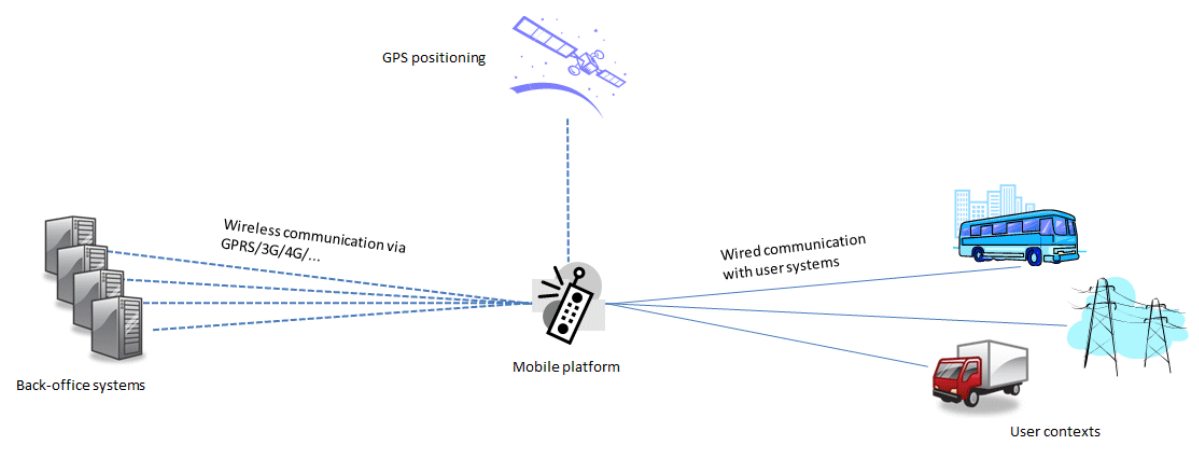

Fig. 3. Platform structure

After installation, the platform allows the customer to access the unit (e.g. vehicle) remotely and gather data from its sensory devices or issue instructions to any onboard control systems. Marketed to business customers, PlatformCoMobile has been adopted in a wide range of industries, including private security, forestry machinery, public transportation and logistics. The majority of application contexts involve supervising vehicles, but there are also customers that prioritise resilience and utilise the platform in situations where physical access is a concern, e.g. for monitoring highvoltage electrical wiring. As customers rely on PlatformCoMobile to continuously transmit data even under extreme conditions, the platform hardware has been certified to comply with several international standards, including those set by the International Electrotechnical Commission (IEC) regarding heat, cold, vibration, shock and humidity.

In addition to services developed by PlatformCo themselves, other suppliers are also able to deliver their services via the platform following a process of certification and testing. PlatformCo typically form partnerships with these external suppliers that utilise their platform, making sure that the partners are able to deliver their service in exchange for a monthly fee. PlatformCo has made it an explicit policy to not develop any services that imitate or infringe upon partner services, instead prioritising the continued existence of the partner and availability of their expertise. While this may limit profits in the short run, it ensures that PlatformCo is able to attract complementors and offer a diverse portfolio of services via its platform.

\section{$6 \quad$ Results}

The following chapter presents the results of the study and relates them to theoretical constructs. 


\subsection{Digital Options in Platform Design}

PlatformCoMobile qua device has been redesigned in three major steps; the original iteration developed in 1997 and brought to market in 2000. The original intent was not to construct a platform for services, but rather to offer a robust, versatile and secure product for wireless communications. As such, PlatformCoMobile was marketed as a communications device that was sufficiently durable to withstand active service for many years in virtually any environment.

"....if you look back at the first generation... the reason that it looked the way it did is because of the tools and technology that were available at the time. We didn't have $3 G$-networks and the like. It was limited by the technical possibilities available back then. [...] You could say that it was largely a prototype or proof-of-concept that everything could work together."

- COO, PlatformCo

The platform was initially a stand-alone solution for communication that offered a highly limited range of functionality and limited prospects for improvements or additions. However, PlatformCo soon began to see the advantages of expanding upon the functionality of the product. The first major step was taken in 2001 when remote access was enabled. The impetus for this move was not a matter of strategy, but rather convenience. Service and configuration of PlatformCoMobile involved significant amount of travelling to remote locations or even neighbouring countries for technical staff. As maintenance is a continuous process, streamlining this activity translates into significant savings, which is particularly important for a relatively small enterprise like PlatformCo. Hence, economising on maintenance was the primary driver for early development of PlatformCoMobile. The following years saw development of platform functionality that was more related to adding value for users, such as the introduction of "managed services" in 2003, which was a basic form of what is commonly referred to as could services today.

Since the first generation of PlatformCoMobile was not intended as a platform for services, it was neither scalable nor expandable. Hence, the transition to the second generation entailed scrapping the entire architecture and starting from scratch with new hardware and software. While costly in terms of time and resources, it was necessary in order to accommodate new components, e.g. an improved GPS transponder and new I/O-ports that were sought by customers. As the second generation of PlatformCoMobile was technically more advanced, PlatformCo took steps to ensure that services followed suit. 2007 saw the introduction of "device management" - a basic maintenance service that facilitates more advanced services. PlatformCo also furthered modularisation of their services by deconstructing the value-chain into four layers: Data transmission, administration and monitoring, data processing and analysing, and high-level services that are often unique to particular business segments. These layers form a kind of hierarchy where data transmission provides the base and high-level services the apex. As the first three layers are closely related to the platform itself, PlatformCo manages these areas in-house whereas high-level services are a blend of services developed by external partners and those developed by PlatformCo. The interdependencies between layers can become bit convoluted as customers sometimes require specialised hardware in order to enable high-level services. 
“[...] we've devoted our efforts to infrastructure, a platform where we can add content - content as in services. But in this case the sensors will be plugged in down here in order to add content higher up."

- Business area manager, PlatformCo

While the second generation of the platform was scalable in terms of functionality, it did not scale in terms of performance - meaning that PlatformCoMobile could not run certain desired services simultaneously. The subsequent transition to the third (current) generation of hardware did not entail a complete overhaul, but did require scrapping roughly $50 \%$ of the previous architecture.

As it stands, the mobile unit may now be considered a flexible platform that is scalable in terms of functionality as well as performance. More importantly, while the platform can be expressed as a combination of physical components (hardware) and digital components (software), services are merely co-specialised to the software. Hence, it is in some ways accurate to say that the software-component marks the essence of the platform as it stands today. The hardware-product serves as a physical link for communication between the user context and the back-office system, but in terms of the current service model, it is essentially a piece of infrastructure at this point.

"...I see that the product is supposed to enable the services required. So you focus less on how things are performed inside the product, and assume more of a bird's-eye view of what function we're after. Maybe customers also focus less on how things are solved and look to our ability to meet [their] functional requirements. You don't look as much to the product and hardware, but rather the customer that buys a service or functionality and expect it to work. That's what counts."

- COO, PlatformCo

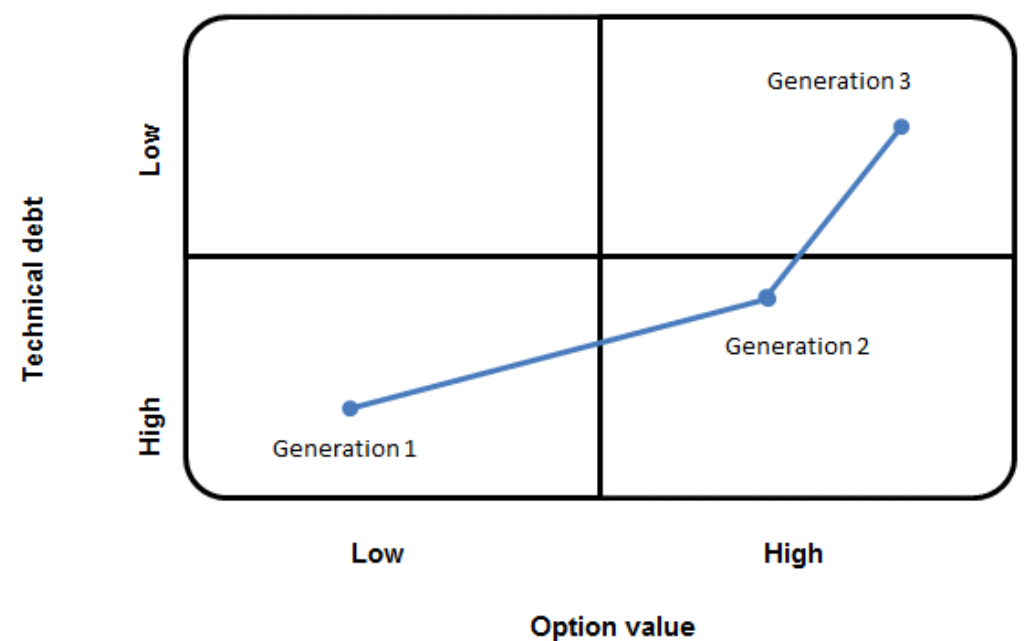

Fig. 4. Design moves at PlatformCo 
The software platform can be modified to accommodate virtually any hardware as is evident by the fact that PlatformCo still has hardware from the first and second generations in active use. It is therefore feasible to run some services on other digital devices, such as smartphones. While this could make quality assurance an issue, PlatformCo has based many features in its platform upon explicit customer requirements or business opportunities. A rough estimate of influences in platform design puts the ratio between explicit customer demands and designer discretion at 40-60, indicating that PlatformCo has cultivated a very pragmatic approach to quality as well as design. All three generations of the physical device have been designed by PlatformCo themselves, but have been based upon readily available standardised components as customisation would be prohibitively expensive. The evolution of the platform is therefore related not only to customer requirements, but also to what technology is available at a competitive price.

\subsection{Real Options in Platform Applicability}

The idea to utilise PlatfomCoMobile as a platform for services as opposed to a specialised product for wireless communication gradually developed via several interim stages, such as the introduction of managed services in 2003 and a concerted transition from product to systems in 2004. While these events were important for the development of the platform as such, it was still limited to the finite resources of PlatformCo and largely propelled by their core competence, i.e. the development of technical solutions for secure communication. In 2005, PlatformCo adopted a partner strategy whereby they actively sought out firms that offered applications or services that were requested by current or potential platform customers. The advantage of partnering in this manner is bilateral. The partners sought out are highly competent in their respective field, adding cutting-edge services to the portfolio of solutions that PlatformCo can market as part of their platform. Conversely, the communications infrastructure provided via PlatformCoMobile essentially enables partners to blackbox the issue of communication and focus on what data is being transmitted rather than how it is transmitted. Moreover, the aggregated network of partners could handle contracts and clients that are too big for any one supplier to manage on their own.

"We see everything that we think and do as a network, and I think...that is the way one should proceed to survive the future. These [big] companies that want it all, they won't be able to pull it off as things are moving too fast [...] you have to find the cutting-edge and then fit the puzzle together."

- CEO, PlatformCo

A salient driving force behind the move towards services was the recalcitrance of customers towards paying for infrastructure (i.e. hardware). Explaining the merits of a platform can often be a challenge as the term does not readily convey a sense of benefit or utility. Familiarising oneself with different industries - or finding partners with the requisite knowledge - has proven to be a significant factor in the ability to successfully market services rather than products. 
“...nobody is really in the market for a platform. What they want is a solution. [...] If you then look at public transportation - the bus-ecosystem - there we've learnt how the industry works in the Nordic countries in order to supply the functionality that they actually want from this platform. In doing so it has suddenly turned into a solution."

- Business area manager, PlatformCo

The transition from product to services has involved working in closer proximity to customers, trying to comprehend the mind-set of a wider range of stakeholders. The business is no longer comprised of engineers who sell products to other engineers, but rather engineers developing services that everyday users can comprehend. Engaging with customers under these circumstances often entails working in close proximity to clarify a problem, deconstruct it, identify relevant causal factors, and then conceptualise feasible services that can alleviate or resolve the issue. Once services have been identified, they are matched to the current offerings available via partners. In cases where obvious match is found, PlatformCo scans the market for providers who offer services that conform to the perceived requirements. If a supplier is found, the company initiates contact and investigates the possibility of a partnership using the business opportunity as a tangible motive. If no suitable solution is found, then the engineers at PlatformCo can fill this "gap" themselves by developing a new service based on the capabilities of their platform.

"The classic example is the children's room with pieces of [building blocks] all over the ground. You can build anything with it, but you need to know what to build, how to do it, where you find the pieces and so on. The next step is to package it in a box. The third step is to categorise the different models with a description and a picture. It's about knowing the industry - for instance what the bus driver needs. Before you know that you cannot package a solution."

- Business area manager, PlatformCo

Learning how an industry works and what it needs is a time-consuming and laborious process. It does however leave in its wake the added boon of naturalising the interactions with customers in that business segment. The need to go into technical detail diminishes, leaving PlatformCo and customers free to stick with the practical concern of how to integrate the solution into the business rather than debate technologies and communication protocols. While PlatformCo strives to package their services as ready-to-order solutions, the practical reality of adapting to a variety of customers and industries limits the applicability of this approach. The efficacy of the platform is dependent upon the ability to integrate it into a given context (e.g. a vehicle) and relay desired data to a corresponding back-office system. As it is not uncommon for customers to employ an eclectic variety of hardware and machinery, the engineers and developers at PlatformCo often find themselves working alongside customers in solving novel problems related to localised integration. 
“It's always tough to 'productify' solutions. For instance, one particular solution is intended to work with a truck - we've done that before. But it's pulling a salt spreader from the 1980's. We need signals from that as well, so we're back to customisation again. [...] That's the way it is with our customers-machinery from the 80 's meets tablets from last year."

- Business area manager, PlatformCo

The initial installation of the platform always requires a certain amount of manhours depending on the context. However, following the initial integration of the platform, services are activated and managed remotely via back-office systems as per customer request. In many cases, this is tantamount to enabling remote connectivity in machinery that was never designed to facilitate this feature. The sudden reality of taking a fleet of vehicles to an online-world can foster new perspectives as one improvement can snowball into new ideas of how to utilise the new infrastructure. It is therefore not uncommon for the customer to come up with several new ideas or suggestions on how they would like to use the platform in the months and years after the initial installation.

\section{Discussion}

The application of digital platforms as a means to facilitate modularity of physical products holds great potential, but also significant complexity. In the present study, we have illustrated the evolution of PlatformCoMobile in three major design moves, originating as a stand-alone solution for communication that offered a highly limited range of functionality, evolving to a connected product able to deliver a range of services, and ending up as the current scalable service-platform for customers operating in several industries.

The significance of digital options is of particular relevance when taking the leap from product evolution to platform evolution. A product is a stand-alone device that alleviates or solves current problems. You may use such a device to deliver services to customers who want simple, purposeful solutions that meet their present needs. Product providers may improve upon their product in relative isolation as improvements are typically implemented in the form of a new version of the product. Platforms differ in at least two respects. First, the underlying motivation for having platforms is to afford changes to individual components that allow the structure as a whole to evolve as needed. Second, (industry) platforms are intended to serve as a hub or shared structure that enables or simplifies interactions between parties. As such, the platform may be regarded as an infrastructure [46] that connects supplier offerings to customer needs.

The difficulty in evaluating platforms is inherent in its vicarious nature. Set against the basic premise of financial options, platforms ostensibly behave in an inverse manner. Rather than a small amount, adopters pay a significant portion of the investment up front in order to access the platform. As suggested by Taudes et al. [13], one way to justify the investment is to evaluate each function permitted by the platform in isolation and tally the result. The present study illustrates that the platform provider 
can facilitate this through either pre-packaged offerings as real options, or by participating in a process of sense-making to develop nascent shadow options present in the operating environment of the adopter. Additionally, the fluid nature of digital materiality is highly commensurate with the mobility of financial assets that provide part of the underpinnings for real options. Digital platforms allow adopters to either consciously hold an option (e.g. on a particular service or application) for a lengthy period of time before acting upon it, or gradually develop shadow options into real options as they come to better understand the platform or identify new organisational needs. Hence, digital platforms can be said to promote incremental decision-making with the notable exception of the physical artefact that houses the digital content.

Digitalisation allows physically non-modular devices to be modified with new software and content, potentially granting them some of the versatility of platforms. That being said, the platform provider must weigh design moves more carefully when developing a platform. A product may to a greater extent be viewed as an independent device with fixed properties, enabling the designer to limit the scope of variables. A (digital) platform may allow the designer considerable leeway with regards to amending those aspects that are obscured to the outside, but cannot redesign physical interfaces or enabling software with the same sense of carte blanche. Alterations must take into consideration an installed base of complementors and users that integrate the platform in a wide variety of local systems for an equally wide variety of purposes. In effect, myopic design moves made to improve the operations of the device could simultaneously incur technical debt for the platform if they are not in keeping with what partners expect or customers require.

Last but not least, evaluating investments on an individual basis may be disadvantageous as it limits one's ability to see the whole picture [47]. This is especially salient when applied to IT as one must usually take compatibility with extant systems into consideration [15]. Options theory ostensibly flies in the face of this reasoning as it advocates incremental decision making under conditions where each option is to some degree perceived as an encapsulated entity. However, when applied to a platform as in the present case study, a case-by-case perception of the different individual services appears a feasible approach as it provides a clearer case for acceptance or rejection when compared to a whole suite of services. Furthermore, the digitised nature of the services makes them inherently flexible. Once the platform qua infrastructure is in place, services can be switched on and off with short notice. Hence, adoption or cancellation of services enabled by digital platforms offers the malleability presupposed by options theory. If anything, an options perspective may be advantageous when seeking to balance a "portfolio" of different services that can enhance the firm's processes or knowledge.

\section{Conclusions}

In this paper, we argue that options theory can contribute to our understanding of digital platforms both as phenomena as well as enabling tools. We employ two conceptions of options theory, real options and digital options, and apply them to case study of a digital platform developed over the course of 13 years by an SME operating in Northern Europe. Using digital options in the form of design capital, we are 
able to plot the evolution of the artefact as an operand resource and see how design moves impact the transition from product to platform. Real options theory provide the other half of the discourse by showing that options are unavailable until they emerge into consciousness following a process of sense-making. In establishing a nascent platform, there is much to be gained by the platform provider in facilitating this sensemaking as each new realisation is another potential sales argument.

Objects and services enabled by digital platforms ostensibly lend themselves to the end-user simplicity of real options due to the flexibility of digital materiality. A possible avenue for future research would be to further explore the relation between design and application, e.g. by studying the relationship between real options and technology affordances.

\section{References}

1. Baldwin, C., Woodard, J.: The Architecture of Platforms: A Unified View. In: Gawer, A. (ed.) Platforms, Markets and Innovation, pp. 19-44. Edward Elgar, Cheltenham (2009)

2. Eisenmann, T., Parker, G., Van Alstyne, M.W.: Strategies for Two-sided Markets. Harvard Business Review 84(10), 92-101 (2006)

3. Eisenmann, T., Parker, G., Van Alstyne, M.: Platform Envelopment. Strategic Management Journal 32(12), 1270-1285 (2011)

4. Eisenmann, T., Parker, G., Van Alstyne, M.W.: Opening Platforms: How, When, and Why? In: Gawer, A. (ed.) Platforms, Markets and Innovation, pp. 131-162. Edward Elgar, Cheltenham (2009)

5. Bodreau, K.J., Haigu, A.: Platform Rules: Multi-sided Platforms as Regulators. In: Gawer, A. (ed.) Platforms, Markets and Innovation, pp. 163-191. Edward Elgar, Cheltenham (2009)

6. Wareham, J., Fox, P., Cano Giner, J.L.: Technology Ecosystem Governance. ESADE Business School Research Paper 225-2 (2013)

7. Vargo, S.L., Lusch, R.F.: Evolving to a New Dominant Logic for Marketing. Journal of Marketing 68(1), 1-17 (2004)

8. Nambisan, S.: Information Technology and Product/Service Innovation: A Brief Assessment and Some Suggestions for Future Research. Journal of the Association for Information Systems 14(4), 215-226 (2013)

9. Dos Santos, B.: Justifying Investment in New Information Technologies. Journal of Management Information Systems 7(4), 71-89 (1991)

10. Benaroch, M., Kauffman, R.J.: Justifying Electronic Banking Network Expansion Using Real Options Analysis. MIS Quarterly 24(2), 197-225 (2000)

11. Benaroch, M., Jeffery, M., Kauffman, R.J., Shah, S.: Option-based Risk Management: A Field Study of Sequential Information Technology Investment Decisions. Journal of Management Information Systems 24(2), 103-140 (2007)

12. Ghosh, S., Li, X.: A Real Options Model for Generalized Meta-Staged Projects-Valuing the Migration to SOA. Information Systems Research 24(4), 1011-1027 (2013)

13. Taudes, A., Feurstein, M., Mild, A.: Options Analysis of Software Platform Decisions: A Case Study. MIS Quarterly 24(2), 227-243 (2000)

14. Fichman, R.G.: Real Options and IT Platform Adoption: Implications for Theory and Practice. Information Systems Research 15(2), 132-154 (2004) 
15. Sandberg, J., Mathiassen, L., Napier, N.: Digital Options Theory for IT Capability Investment. Journal of the Association for Information Systems (forthcoming, 2014)

16. Suarez, F., Cusumano, M.: The Role of Services in Platform Markets. In: Gawer, A. (ed.) Platforms, Markets and Innovation, pp. 77-98. Edward Elgar, Cheltenham (2009)

17. Cusumano, M.A.: Platforms Versus Products: Observations from the Literature and History. History and Strategy 29, 35-67 (2012)

18. Tiwana, A., Konsynski, B., Bush, A.A.: Research Commentary-Platform Evolution: Coevolution of Platform Architecture, Governance, and Environmental Dynamics. Information Systems Research 21(4), 675-687 (2010)

19. Gawer, A.: Platform Dynamics and Strategies: From Products to Services. In: Gawer, A. (ed.) Platforms, Markets and Innovation, pp. 1-18. Edward Elgar, Cheltenham (2009)

20. Le Masson, P., Weil, B., Hatchuel, A.: Platforms for the Creation of Platforms: Collaborating in the Unknown. In: Gawer, A. (ed.) Platforms, Markets and Innovation, pp. 273-375. Edward Elgar, Cheltenham (2009)

21. Kallinikos, J., Aaltonen, A., Marton, A.: The Ambivalent Ontology of Digital Artifacts. MIS Quarterly 37(2), 357-370 (2013)

22. Tilson, D., Lyytinen, K., Sørensen, C.: Research Commentary-Digital Infrastructures: The Missing IS Research Agenda. Information Systems Research 21(4), 748-759 (2010)

23. Yoo, Y., Boland, R.J., Lyytinen, K., Majchrzak, A.: Organizing for Innovation in the Digitized World. Organization Science 23(5), 1398-1408 (2012)

24. Yoo, Y., Henfridsson, O., Lyytinen, K.: Research Commentary-The New Organizing Logic of Digital Innovation: An Agenda for Information Systems Research. Information Systems Research 21(4), 724-735 (2010)

25. Tilson, D., Sorensen, C., Lyytinen, K.: Platform Complexity: Lessons from the Music Industry. In: Proceedings of the 46th IEEE Hawaii International Conference on System Sciences, Maui, USA (2013)

26. Black, F., Scholes, M.: The Pricing of Options and Corporate Liabilities. The Journal of Political Economy 81(3), 637-654 (1973)

27. Adner, R., Levinthal, D.A.: What is Not a Real Option: Considering Boundaries for the Application of Real Options to Business Strategy. Academy of Management Review 29(1), 74-85 (2004)

28. Bowman, E.H., Hurry, D.: Strategy through the Option Lens: An Integrated View of Resource Investments and the Incremental-choice Process. Academy of Management Review 18(4), 760-782 (1993)

29. Weick, K.E., Sutcliffe, K.M., Obstfeld, D.: Organizing and the Process of Sense-making. Organization Science 16(4), 409-421 (2005)

30. March, J.G.: Exploration and Exploitation in Organizational Learning. Organization Science 2(1), 71-87 (1991)

31. Orlikowski, W.J., Gash, D.C.: Technological Frames: Making Sense of Information Technology in Organizations. ACM Transactions on Information Systems 12(2), 174-207 (1994)

32. Ciborra, C.U.: The Platform Organization: Recombining Strategies, Structures, and Surprises. Organization Science 7(2), 103-118 (1996)

33. Cohen, W.M., Levinthal, D.A.: Absorptive Capacity: A New Perspective on Learning and Innovation. Administrative Science Quarterly 25(1), 128-152 (1990)

34. McGrath, R.G.: A Real Options Logic for Initiating Technology Positioning Investments. Academy of Management Review 22(4), 974-996 (1997)

35. Brynjolfsson, E.: The Productivity Paradox of Information Technology. Communications of the ACM 36(12), 66-77 (1993) 
36. Fichman, R.G., Keil, M., Tiwana, A.: Beyond Valuation: "Option Thinking” in IT Project Management. California Management Review 47(2), 74-95 (2005)

37. Sambamurthy, V., Bharadwaj, A., Grover, V.: Shaping Agility Through Digital Options: Reconceptualizing the Role of Information Technology in Contemporary Firms. MIS Quarterly 27(2), 237-263 (2003)

38. Overby, E., Bharadwaj, A., Sambamurthy, V.: Enterprise Agility and the Enabling Role of Information Technology. European Journal of Information Systems 15(2), 120-131 (2006)

39. Barney, J.: Firm Resources and Sustained Competitive Advantage. Journal of Management 17(1), 99-120 (1991)

40. Karimi, J., Somers, T.M., Bhattacherjee, A.: The Role of ERP Implementation in Enabling Digital Options: A Theoretical and Empirical Analysis. International Journal of Electronic Commerce 13(3), 7-42 (2009)

41. Woodard, C.J., Ramasubbu, N., Tschang, F.T., Sambamurthy, V.: Design Capital and Design Moves: The Logic of Digital Business Strategy. MIS Quarterly 37(2), 537-564 (2013)

42. Zittrain, J.L.: The Generative Internet. Harvard Law Review 19(7), 1974-2040 (2006)

43. Yin, R.K.: Case Study Research - Design and Methods, 4th edn. Sage Publications, Thousand Oaks (2009)

44. Creswell, J.W.: Qualitative Inquiry \& Research Design - Choosing among Five Approaches, 2nd edn. Sage Publications, Thousand Oaks (2007)

45. Kvale, S., Brinkmann, S.: Interviews: Learning the Craft of Qualitative Research Interviewing, 2nd edn. Sage Publications, Thousand Oaks (2009)

46. Star, S.L., Ruhleder, K.: Steps Toward an Ecology of Infrastructure: Design and Access for Large Information Spaces. Information Systems Research 7(1), 111-134 (1996)

47. Teece, D.J.: Explicating Dynamic Capabilities: The Nature and Microfoundations of (Sustainable) Enterprise Performance. Strategic Management Journal 28(13), 1319-1350 (2007) 